\title{
Yield Comparison of Hybrid Agaricus Mushroom Strains as a Measure of Resistance to Trichoderma Green Mold
}

\author{
M. G. Anderson, D. M. Beyer, and P. J. Wuest, Department of Plant Pathology, The Pennsylvania State Univer- \\ sity, 210 Buckhout Lab, University Park 16802
}

\begin{abstract}
Anderson, M. G., Beyer, D. M., and Wuest, P. J. 2001. Yield comparison of hybrid Agaricus mushroom strains as a measure of resistance to Trichoderma green mold. Plant Dis. 85:731-734.

Commercially available strains of hybrid white, hybrid off-white, and brown Agaricus bisporus mushrooms were compared for resistance to green mold caused by Trichoderma harzianum biotype 4 (Th4). Seven mushroom spawn strains were assessed for total weight of mushrooms (grams per $0.1 \mathrm{~m}^{2}$ ) with or without the addition of an aqueous Th4 spore suspension added at spawning time. Cropping studies were conducted at the Mushroom Research Center (Pennsylvania State University) to emulate commercial growing operations. Excessive spawn handling had no significant effect on development of green mold. Severity of green mold was related to time between infestation and green mold appearance, with more significant yield losses occurring when green sporulation was detected early in production. Significant differences in yield were measured among mushroom strains in response to Th4 infestation. Hybrid white strains were extremely susceptible, with a mean yield loss of $96 \%$. Hybrid off-white strains exhibited intermediate susceptibility, with mean yield losses of 56 to $73 \%$. Brown strains were highly resistant, with mean yield losses of 9 to $16 \%$. From these findings, we report the existence of green mold resistance, with a continuum of resistance among spawn strains. The findings suggest use of brown strains to manage green mold outbreaks, particularly where benomyl resistance in Trichoderma spp. is a threat.
\end{abstract}

Pennsylvania mushroom growers produced 442 million pounds of Agaricus bisporus (Lange) Imbach mushrooms in the 1999-2000 season, supplying half of the Agaricus crop in the United States and leading all states in production (11). Producers of cultivated mushrooms must manage pathogens similar to those traditionally encountered in plant production, including Pseudomonas spp. causing bacterial blotch and Verticillium fungicola, causal agent of dry bubble (8). Trichoderma harzianum Rifai appeared in Pennsylvania in the early 1990s as the causal agent of green mold epidemics in cultivated mushroom beds. Green mold is characterized by large areas of dense green sporulation on compost and casing surfaces which result in dramatic mushroom yield reduction. From 1994 to 1996, crop losses in Pennsylvania ranged from 30 to $100 \%$. Since the onset of the disease in Pennsylvania, crop losses have been estimated in excess of $\$ 30$ million (17). The causal agent of this crop loss was identified as T. harzianum biotype 4 (Th4).

Corresponding author: D. M. Beyer

E-mail: dmb8@psu.edu

This research was supported by Mushroom Industry Farm Based Agricultural Research Program.

Accepted for publication 15 March 2001.

Publication no. D-2001-0511-02R

(C) 2001 The American Phytopathological Society
Th4 was subsequently found to be genetically distinct from pre-epidemic isolates of Trichoderma from Pennsylvania farms as well as Trichoderma spp. used as biocontrol agents of plant pathogenic fungi $(3,12,15)$. Spores are easily carried by workers, insects, and contaminated equipment so that infestations are quickly spread from crop to crop. Stringent sanitation coupled with the use of the fungicide benomyl applied to spawn grains has resulted in management of green mold (2). However, concerns of fungicide resistance in Trichoderma spp. spurs the ongoing research of the interactions between $A$. bisporus and $T$. harzianum $(5,6)$.

In order to develop sustainable green mold management strategies, a thorough understanding of the relationship between Trichoderma spp. and A. bisporus is required. Many factors have been postulated for the occurrence of the green mold organism in association with $A$. bisporus $(5,10,13)$. These include but are not limited to the following: changes in composting procedures or raw ingredients, reduced attention to sanitation and post-crop steamoff programs, and changes in spawn production or availability. During the early 1980s, spawn suppliers began offering spawn hybrids. Mushroom hybrids were created by Fritsche using monospore isolates which were then crossed with other monosporic isolates and tested for compatibility (4). Spores were then collected from fertile combinations to test the
F2 generation for novel fruiting body characteristics. Approximately 40 monospore cultures of the F2 generation were tested for commercial suitability. Selection resulted in four successful hybrids formed by crosses of white and off-white types. Of those four hybrids, two were subsequently introduced into commercial production, Horst U1 and Horst U3. The distinction between prehybrid and hybrid spawn strains is important because prehybrid strains were primarily obtained using multispore culture. The purpose of the current research was to examine the commercially available hybrid strains for resistance to green mold, along with commercially available brown strains which were not a part of the hybrid selection process.

The cultivated mushroom A. brunnescens was found to exhibit differential susceptibility to various compost-invading fungi, including T. viride (7). Recent studies indicate white $A$. bisporus mushrooms are considerably more susceptible to bacterial blotch than brown mushrooms (9). In addition, it has been observed that there are differences in green mold susceptibility among noncommercial mushroom strains, with brown strains showing greater resistance to green mold infestation (2). The objective of this study was to examine commercially available mushroom strains with a range of cap colors for differences in susceptibility to Th4 and to quantify yield losses associated with the various mushroom strains.

\section{MATERIALS AND METHODS}

Seven cropping studies were conducted at the Mushroom Research Center at the Pennsylvania State University, University Park. A bag crop system for growing mushrooms was employed using spawn strains selected on the basis of commercial availability and popularity with local growers. Cultural practices for each crop were standardized for phase I and phase II composting, spawning, and casing. Each bag contained $22.7 \mathrm{~kg}$ of compost, prepared by the standard procedure at the Mushroom Testing Demonstration Facility (14). Compost was supplemented with SpawnMateII SE (SpawnMate Inc., Watsonville, CA) at $4 \%$ on a wet weight basis. Compost was spawned by hand mixing $110 \mathrm{~g}$ of commercial grain spawn that was allowed to warm to room temperature overnight. Commercially available hybrid white, hybrid offwhite, and brown mushroom strains were 
compared. A distinction was made between the original (primary) hybrid off-white (Horst U1) and hybrid off-white strains assumed to be derived from the primary source (4). Differences in resistance were measured primarily by yield response, based on total weight (grams per $0.1 \mathrm{~m}^{2}$ ) of mushroom harvested. In addition, colonization rates of both $A$. bisporus and Th4 were visually assessed.

Trichoderma cultures were maintained on 3\% malt extract agar amended with streptomycin sulfate at $0.1 \mathrm{~g} /$ liter to inhibit bacterial growth. Mushrooms were grown with or without an aqueous $1-\mathrm{ml}, 1 \times 10^{7}$ spore suspension of a 7-day culture of Th4 in sterile water pipetted at the center of the compost surface at spawning. The spore suspension was deposited $2.5 \mathrm{~cm}$ below the compost surface to prevent inoculum desiccation. Visible spawn growth based on percent colonization of the surface of the compost or casing $(0=$ no colonization, $1=1$ to $20,2=21$ to $40,3=41$ to $60,4=$ 61 to 80 , and $5=81$ to $100 \%$ colonization) and visible green mold ( 0 to 5 ) were assessed regularly during the cropping cycle. Days from spawning (infestation) until the first appearance of Th4 sporulation was recorded for each strain. Yield data was measured as number of mushrooms and total weight (grams per $0.1 \mathrm{~m}^{2}$ ). The growing area of one bag is $0.1 \mathrm{~m}^{2}$. Standard growing conditions were used, with a spawn run incubation temperature of $25.5^{\circ} \mathrm{C}$ and casing with moistened unpasteurized peat moss and limestone (14). Fruiting bodies were harvested for three successive flushes of mushrooms. A completely random experimental design was used to position the 30 to 48 bags per crop in a growing room. Treatment design was factorial, variable one indicating spawn type and variable two designating Th4 infestation. Spawn types were hybrid white (HW), hybrid off-white 1 (HOW1), hybrid off-white 2 (HOW2), hybrid off-white 3 (HOW3), brown 1 (BR1), brown 2 (BR2), or brown 3 (BR3). Th4 infestation was either negative (-) or positive (+). Treatments were replicated four or five times within a crop, as well as replicated in three separate crops, with the exception of HOW1, which was used in four crops.

In the initial crop, two HOW strains were used to determine if excessive spawn handling contributed to the incidence of green mold as outlined below. Spawn consisted of autoclaved cereal grain that had been seeded with A. bisporus mycelium. While spawn is stored in refrigerators until used, the mycelium grows, knitting the grain tightly together by a hyphal network. Bags of spawn were physically agitated before use to divide spawn clumps into individual grains for more even distribution in the compost. Excessive spawn handling consisted of placing the spawn in large plastic bags and manipulating it for several minutes, comparable to a grower dropping a spawn bag against a tabletop several times to loosen the grains. In the initial crop, several other factors were tested for their effects on green mold development. Unspawned compost was infested with Th4 to ascertain if the presence of $A$. bisporus was required for green mold to develop. Another treatment consisted of rye grain uninoculated with $A$. bisporus mycelium being added at the typical spawn rate to determine if Th4 merely utilized the rye grain as a nutrient source.

Six subsequent crops compared one HW strain, three HOW strains, and three BR strains for resistance to green mold. All spawn was obtained from commercial suppliers in the United States. All results are presented based on spawn color rather than individual spawn strain numbers. For example, hybrid off-white 1 is referred to as HOW1. HOW 1 is a primary Horst U1 strain while HOW2 and HOW3 strains are assumed to be derived from U1. HW is assumed to be derived from Horst U3. Among the brown strains there is no derivation implied.

All statistical analysis was performed using the general linear models and analysis of variance procedures in Minitab (State College, PA). Means were separated according to Fisher's least significant difference test at 0.05 probability level.

\section{RESULTS}

The initial crop contained two hybrid off-white mushroom strains, HOW1 and HOW2, and tested the effects of excessive spawn handling prior to use. Results indicated that excessive spawn handling did not contribute to the development of green mold (Table 1). There were no significant differences in yield between treatments that were handled excessively and infested

Table 1. Yield comparison of two hybrid off-white (HOW) Agaricus strains for interactions of green mold caused by Trichoderma harzianum biotype $4(\mathrm{Th} 4)$ and excessive spawn handling $(n=4)^{\mathrm{z}}$

\begin{tabular}{|c|c|c|c|}
\hline Spawn strain & Th4 & Excessive spawn handling & Yield $\left(\mathrm{g} / 0.1 \mathrm{~m}^{2}\right)$ \\
\hline \multirow[t]{3}{*}{ HOW1 } & - & - & $2,743 \mathrm{~b}$ \\
\hline & + & - & $274 \mathrm{c}$ \\
\hline & + & + & $291 \mathrm{c}$ \\
\hline \multirow[t]{3}{*}{ HOW2 } & - & - & $3,759 \mathrm{a}$ \\
\hline & + & - & $1,549 \mathrm{bc}$ \\
\hline & + & + & $1,554 \mathrm{bc}$ \\
\hline
\end{tabular}

$\mathrm{z}_{-}=$treatment not administered, $+=$treatment administered. Means within a column followed by the same letter are not significantly different $(P<0.05)$. with green mold and treatments that were not handled excessively and infested with green mold. Observations from this crop indicated that the presence of $A$. bisporus was necessary for the development of green mold. Although no yield comparisons could be made for unspawned compost or compost with grain added that was uncolonized by spawn, observations on colonization by A. bisporus and Trichoderma spp. were made. Both of these treatments, the unspawned compost and uncolonized grain, were infested with Th4 at the same time as normally spawned treatments, but did not support the expression of green mold. In contrast, Trichoderma spp.-infested compost containing $A$. bisporus developed extensive green mold on compost and casing surfaces.

The cumulative results of the seven cropping trials are reported in Table 2. The results show yields of HW and HOW strains are significantly reduced due to infestation with Th4. Although BR strains exhibit some yield losses, they are not as severely affected as the less-pigmented strains of A. bisporus.

To examine the susceptibility of the various strains to green mold infestation, yield losses were analyzed. Percentage yield loss for the different strains as compared with the yield of the respective strains in the absence of Trichoderma spp. is shown in Figure 1. The HW strain had a mean yield loss of 94\%. Yield losses among HOW strains ranged from $58 \%$ to $75 \%$. BR strain yield losses were between 9 and $16 \%$. This analysis shows that yield losses were significantly higher in HW and HOW strains when compared to BR strains.

Days from infestation until the first appearance of green mold is shown in Figure

Table 2. Comparison of seven spawn types for effects of Trichoderma green mold on yieldy

\begin{tabular}{lccc}
\hline $\begin{array}{l}\text { Spawn } \\
\text { strainz }\end{array}$ & Th4 & $\boldsymbol{n}$ & $\begin{array}{c}\text { Yield } \\
\left(\mathbf{g} / \mathbf{0 . 1} \mathbf{~ m}^{\mathbf{2}}\right)\end{array}$ \\
\hline HOW1 & - & 16 & 3,097 \\
& + & 16 & $1,356^{*}$ \\
HOW2 & - & 12 & 3,668 \\
& + & 12 & $975 *$ \\
HOW3 & - & 12 & 3,526 \\
& + & 12 & $1,467 *$ \\
HW & - & 12 & 4,128 \\
& + & 12 & $234 *$ \\
BR1 & - & 14 & 3,810 \\
& + & 14 & 3,289 \\
BR2 & - & 14 & 3,870 \\
& + & 14 & 3,417 \\
BR3 & - & 14 & 3,691 \\
& + & 14 & 3,391 \\
\hline
\end{tabular}

y Yield is expressed as the mean of total bag weight $\left(\mathrm{kg} / \mathrm{m}^{2}\right)$ for seven cropping experiments; $-=$ treatment not administered, $+=$ treatment administered, and $*$ indicates significant reduction of yield $(P<0.05)$ by Trichoderma harzianum biotype 4 (Th4) compared to uninfested control of the same strain.

z HOW = hybrid off-white, HW = hybrid white, and $\mathrm{BR}=$ brown strains of Agaricus bisporus. 
2. Compost containing the HW strain HW showed green mold in an average of 12 days. Strains HOW1, HOW2, and HOW3 developed symptoms 13 to 24 days after infestation. Casing is typically applied 14 days after spawning, and this is the critical stimulant for basidiomycete pin formation. If green mold appears at this time in the cropping cycle, the first flush is greatly impacted. In contrast, BR strains did not support green mold symptoms until at least 30 days after infestation. The first flush is usually the most productive, and the development of green mold at this later time in the second and third flushes did not result in significant crop loss.

\section{DISCUSSION}

The development of green mold, visually apparent green sporulation of Th4, requires the presence of $A$. bisporus mycelium in the compost. Neither unspawned compost nor compost to which sterilized but $A$. bisporus-free rye grain was added supported the growth of green mold. Even in compost where Th4 was visible growing on the rye grains, or where Th4 had been reisolated, there was no dramatic development of green mold that was visible in compost containing A. bisporus spawn. This, coupled with the fact that green mold development followed colonization by $A$. bisporus, suggests either a parasitic enzymatic interaction between the fungi or a breakdown of nutrients by $A$. bisporus that the Trichoderma sp. then utilized. The nature of the hyphal and chemical interactions between the A. bisporus mycelium and $T$. harzianum biotype 4 (Th4) have yet to be elucidated.

A study by Boyle suggests that excessive handling of spawn through autoclaving, freezing, or crushing results in more rapid colonization of compost by green

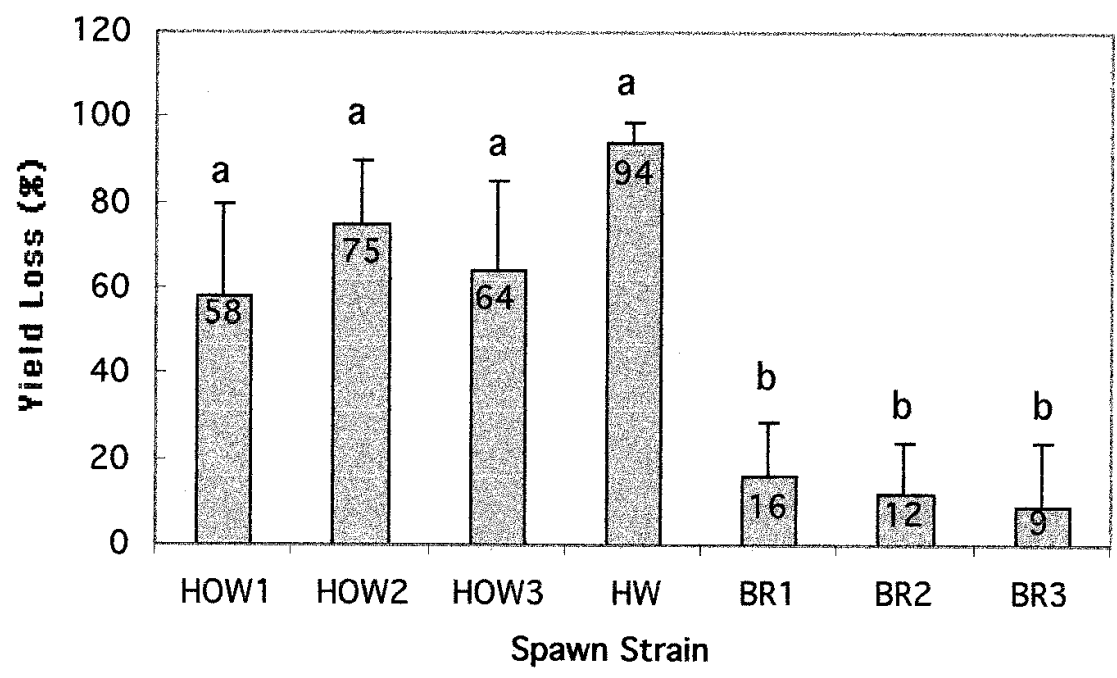

Fig. 1. Yield losses among various hybrid white (HW), hybrid off-white (HOW), and brown (BR) mushroom strains when infested with Trichoderma harzianum biotype 4. Bars with the same letter are not significantly different $(P<0.05)$.

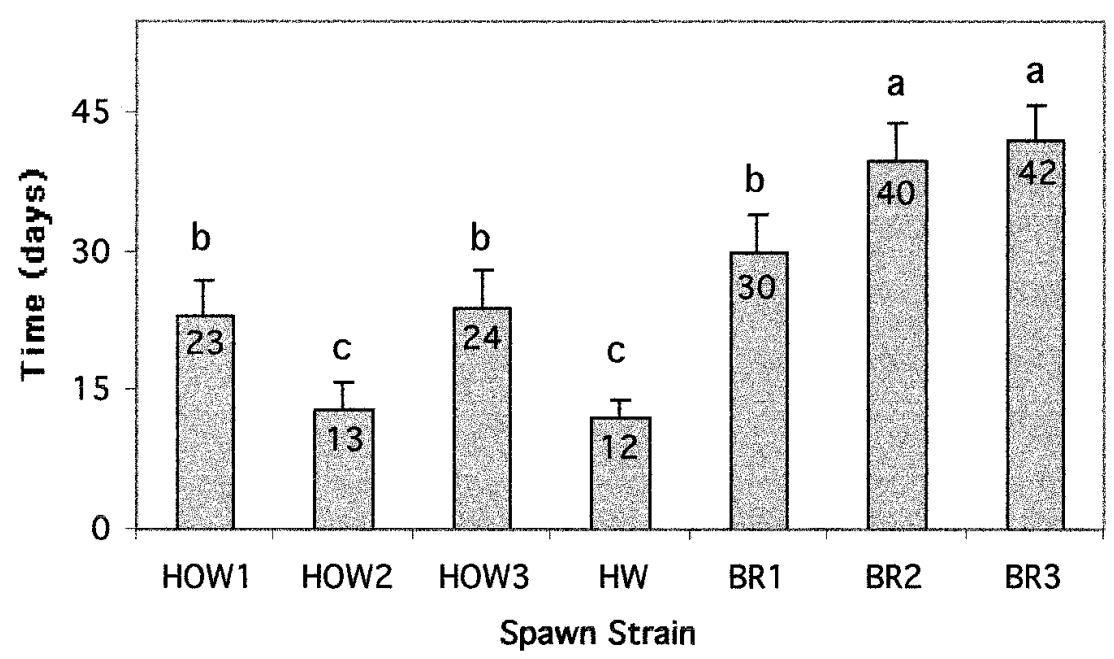

Fig. 2. Days from infestation to first appearance of green mold among hybrid white (HW), hybrid off-white (HOW), and brown (BR) mushrooms. Bars with the same letter are not significantly different $(P<0.05)$. mold (1). Our experiment indicated that typical spawn handling did not confer an advantage for green mold growth. Excessive spawn handling did not significantly contribute to more severe yield losses from green mold. Additional studies are in progress to identify the mode of pathogenesis of Trichoderma spp. with Agaricus mycelium.

Results from these studies indicate that commercially available $A$. bisporus mushroom hybrids of various strain color exhibit differential susceptibility to green mold. The HW strain sustained mean yield losses of $96 \%$, HOW strains exhibited intermediate resistance with yield losses ranging from 56 to $73 \%$, and BR strains displayed mean yield losses of 8 to $14 \%$. The concept can be visualized as a resistance continuum in $A$. bisporus, with greatest susceptibility shown in lightly pigmented strains, and greatest resistance in strains with a heavily pigmented pileus. Interestingly, although brown Agaricus strains display significant resistance to green mold, specialty mushrooms such as shiitake (Lentinula edodes) are highly susceptible (16).

\section{ACKNOWLEDGMENTS}

We thank personnel at the Mushroom Testing Demonstration Facility and Mushroom Research Center for technical support.

\section{LITERATURE CITED}

1. Boyle, D. 1999. Why mushrooms are not wiped out by green mould. Mushroom World 10(5):5-10.

2. Chen, X. 1998. Trichoderma green mold disease on Agaricus bisporus: Evidence for the introduction of a new genotype of the pathogen. Ph.D. thesis. The Pennsylvania State University, University Park.

3. Chen, X., Romaine, C. P., Tan, Q., Schlagnhaufer, B., Ospina-Giraldo, M. D., Royse, D. J., and Huff D. R. 1999. PCR-Based genotyping of epidemic and preepidemic Trichoderma isolates associated with green mold of Agaricus bisporus. Appl. Environ. Microbiol. 65(6):2674-2678.

4. Fritsche, G. 1981. Some remarks on the breeding and maintenance of strains and spawn of Agaricus bisporus and A. bitorquis. Pages 367-385 in: Proc. Int. Sci. Congr. Cultivation Edible Fungi., 11th.

5. Grogan, H. M., Noble, R., Gaze, R. H., and Fletcher, J. T. 1996. Control of Trichoderma harzianum, a weed mould of mushroom cultivation. Proc. 1996 Brighton Crop Prot. Conf. Pests Dis. 1:337-342.

6. Grogan, H. M., Noble, R., Gaze, R. H., and Fletcher, J. T. 1997. Compost inoculation and control of Trichoderma harzianum, a weed mold of mushroom cultivation. Mushroom News 45(4):29-36.

7. Harvey, C. L. 1978. Reaction of three strains of the cultivated mushroom, Agaricus brunnescens Peck, to four compost-invading fungi. M.S. thesis. The Pennsylvania State University, University Park.

8. Harvey, C. L., Wuest, P. J., and Schisler, L. C.. 1982. Diseases, weed molds, indicator molds, and abnormalities of the commercial mushroom, Pages 19-33 in: Penn State Handbook for Commercial Mushroom Growers. The Pennsylvania State University, University Park.

9. Moquet, F., Mamoun, M. RamosGuedes- 
Lafargue, M., Olivier, J. M., and Savoie, J. M. 1998. Differences in susceptibility of Agaricus bisporus strains to bacterial blotch and in natural cap colour related to compost composition. Plant Breed. 117:385-388.

10. Mumpuni, A., Sharma, H. S. S., and Brown, A. E. 1998. Effect of metabolites produced by Trichoderma harzianum biotypes and Agaricus bisporus on their respective growth radii in culture. Appl. Environ. Microbiol. 64(12):5053-5056.

11. National Agricultural Statistics Services. 2000. United States Department of Agriculture. Vg 2-1-2 (8-00).
12. Ospina-Giraldo, M. D., Royse, D. J., Chen, X., and Romaine, C. P. 1999. Molecular phylogenetic analyses of biological control strains of Trichoderma harzianum and other biotypes of Trichoderma spp. associated with mushroom green mold. Phytopathology 89:308-313.

13. Pitblado, R. E., and Rinker, D. L. 1997. Sum. Rep. 39th Mushroom Ind. Short Course, Penn State. June 9-11, 1997. 8(3)63-65.

14. Schroeder, G. M., and Schisler, L. C. 1981. Influence of compost and casing moisture on size, yield, and dry weight of mushrooms. Mushroom Sci. 11:495-509.
15. Seaby, D. 1996. Differentiation of Trichoderma taxa associated with mushroom production. Plant Pathol. 45:905-912.

16. Tokimoto, K., and Komatsu, M. 1995. Selection and breeding of shiitake strains resistant to Trichoderma spp. Can. J. Bot. 73(S1): S962-S966.

17. Wuest, P. J., Anton, L. A., and Beyer, D. M 1996. Mushroom crop losses associated with Trichoderma green mold when compost was infested prior to casing and the casing was CAC'd or deep-scratched. Mushroom Green Mold Round Table. PSU. 43. Pennsylvania State University, University Park. 